TITLE:

\title{
One-Step Synthesis of Dendritic Highly Branched Polystyrenes by Organotellurium-Mediated Copolymerization of Styrene and a Dienyl Telluride Monomer
}

$\operatorname{AUTHOR}(S)$ :

Lu, Yangtian; Yamago, Shigeru

\section{CITATION:}

Lu, Yangtian ... [et al]. One-Step Synthesis of Dendritic Highly Branched Polystyrenes by Organotellurium-Mediated Copolymerization of Styrene and a Dienyl Telluride Monomer. Angewandte Chemie International Edition 2019, 58(12): 3952-3956

ISSUE DATE:

2019-03-18

URL:

http://hdl.handle.net/2433/237368

\section{RIGHT:}

This is the peer reviewed version of the following article:Y. Lu, S. Yamago, Angew. Chem. Int. Ed. 2019, 58, 3952., which has been published in final form at https://doi.org/10.1002/anie.201814566. This article may be used for non-

commercial purposes in accordance with Wiley Terms and Conditions for Use of Self-Archived Versions.; The full-text file will be made open to the public on 18 March 2020 in accordance with publisher's 'Terms and Conditions for SelfArchiving': この論文は出版社版でありません。引用の際には出版社版をご確認ご利用ください。; This is not the published version. Please cite only the published version. 


\section{One-step Synthesis of Dendritic Highly Branched Polystyrenes by Organotellurium-mediated Copolymerization of Styrene and a Dienyl Telluride Monomer}

\author{
Yangtian $\mathrm{Lu}{ }^{[\mathrm{a}]}$ and Shigeru Yamago*[a]
}

\begin{abstract}
Dendritic highly branched polystyrenes (HB-PSts) were prepared by a one-step copolymerization of dienyl telluride $\mathbf{6}$ and St in the presence of organotellurium chain transfer agent 2 . The molecular weight (MW), dendritic generation, and branching density were easily controlled by the ratio of $\mathbf{2}$ to $\mathbf{6}$ to St with maintaining monodispersity. The branching efficiency estimated by a deuteriumlabeling experiment showed that 6 quantitatively (>95\%) served as the branching point. The end group fidelity was high ( 90\%) as determined by the end group transformation to pyrene-derivative. Intrinsic viscosity of the HP-polystyrenes was significantly lower than that of linear polystyrenes and were easily tuned by the branching number and branching density. The method is compatible of various functional groups and chloro and acetoxy-substituted styrenes were also used as a comonomer. A tadpole block copolymer was also synthesized starting from linear PSt as a macroinitiator.
\end{abstract}

Highly branched polymers (HBPs) have attracted a great deal of attention due to their unique topological structure associated with characteristic physical properties, such as a lower intrinsic viscosity, lower glass transition temperature, and a larger number of terminal groups than the corresponding linear polymers. ${ }^{[1]}$ Therefore, HBPs are promising for various applications including lubricants, coatings, drug-delivery vehicles, and catalysts..$^{[2]}$ However, the development of a practical method for synthesizing structurally controlled HBPs has been a significant challenge.

Among HBPs, dendrimers and dendrons are the most precisely controlled three-dimensional (3D) structures, i.e., molecular weight, dispersity, branching number, and branching density. However, the necessity of a multistep synthesis limits their applications in materials science. ${ }^{[3]}$ In contrast, hyperbranched polymers can be easily synthesized by one-step methods, such as 1) the step-growth poly-condensation of $A B_{n}$ monomers and the copolymerization of $A_{2}$ and $B_{n}$ monomers, in which $A$ and $B$ refer to two functional groups that react with each other and $n$ represents the numbers of $B$ groups, ${ }^{[4]}$ and 2 ) selfcondensing vinyl (co)polymerization $(\mathrm{SCV}(\mathrm{C}) \mathrm{P})$ and selfcondensing ring-opening polymerization using the $A B^{*}$ monomer, in which $A$ and $B^{*}$ refer to olefin and initiating groups, respectively. ${ }^{[5]}$ Though some $3 \mathrm{D}$ structural control could be possible by using special conditions, such as emulsion polymerization to avoid intermicellar reactions ${ }^{[6]}$ or the slow addition technique to avoid the step-growth mechanism,,$^{[7]}$ no general method to control the 3D structure has been realized. Only two methods have been reported so far for controlling the

[a] Y. Lu, Prof. Dr. S. Yamago

Institute for Chemical Research, Kyoto University

Uji 611-0011(Japan)

E-mail: yamago@scl.kyoto-u.ac.jp

Supporting information for this article is given via a link at the end of the document.
3D structure of HBPs by chemical means under the polycondensation of $A B_{2}$ monomers. Yokozawa reported the condensation polymerization of an aromatic $A_{2}$ monomer, in which the reactivity of the $B_{2}$ group is enhanced after the monomer is incorporated into a polymer. ${ }^{[8]}$ Gao reported the "click" polymerization of the $\mathrm{AB}_{2}$ monomer, and catalyst-transfer enables the control. ${ }^{[9]}$

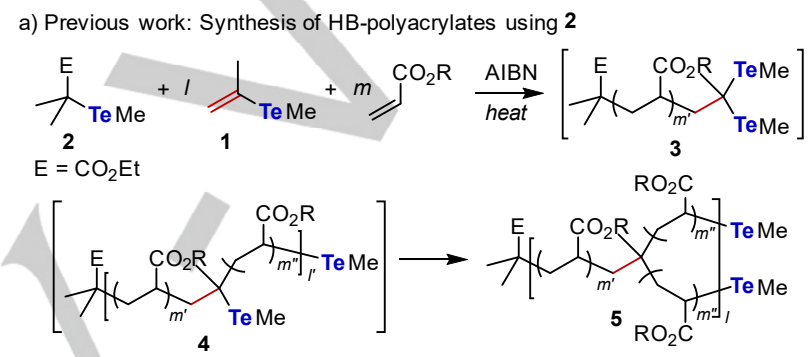

b) This work: Synthesis of HB-polystyrene using 6

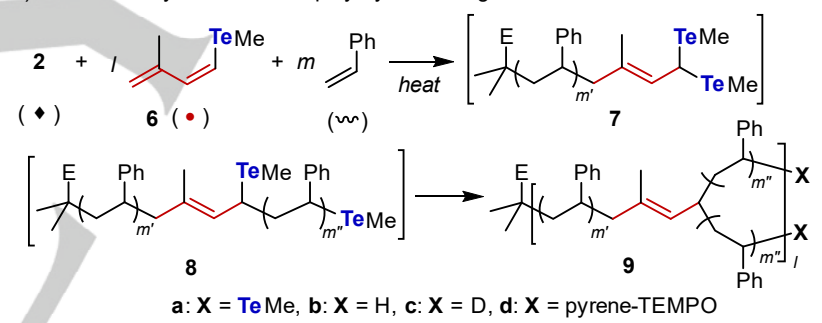

c) Schematic structures of ideal polymer products by changing [6]/[2] ratio

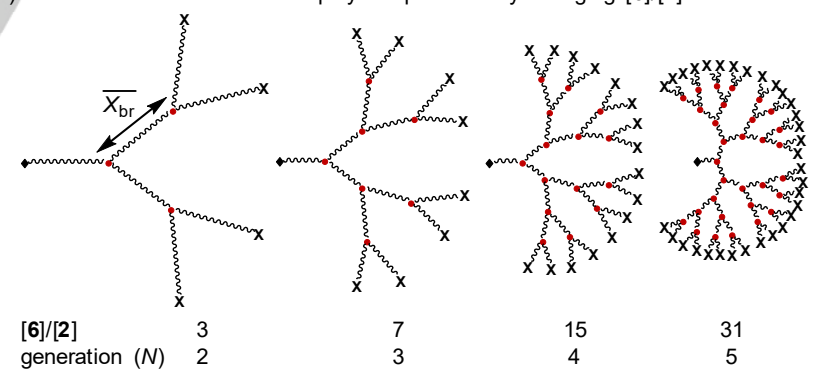

Scheme 1. Synthesis of HBPs by radical copolymerization under organotellurium mediated radical polymerization (TERP).

Recently, we reported a new method for controlling the 3D structure of HBPs by radical polymerization, ${ }^{[10]}$ in which vinyl telluride $\mathbf{1}$ was copolymerized with acrylate monomers in the presence of an organotellurium chain transfer agent 2 used for organotellurium mediated radical polymerization, TERP (Scheme 1). ${ }^{[11]}$ While both 1 and 2 have C-Te bonds that potentially generate the corresponding initiating radicals, 1 does not serve as an initiator due to its high $s p^{2} \mathrm{C}$-Te bond strength compared to the $s p^{3} \mathrm{C}$ - Te bond, such as that in 2. However, once 1 reacts as a monomer forming a dormant species 3 , both $s p^{3} \mathrm{C}$-Te bonds in 
3 are activated and generate new polymer chains giving HB polyacrylates $\mathbf{5}$. The molecular weight, branching density, and branching number of the resulting polymer were easily controlled by the molar ratio of 1,2 , and the acrylate monomer with maintaining a narrow dispersity. This method has significant potential because it is based on radical polymerization, which is the most versatile industrial polymerization method. ${ }^{[12]}$

Despite the novelty and synthetic potential, however, controlled syntheses of HBPs with 1 have been limited for polyacrylates and polyacrylamides. For example, styrene $(\mathrm{St})$ is one of the most important monomers, but it does not copolymerize with 1 . The results are reasonable because $S t$ does not copolymerize with $\alpha$-olefin. ${ }^{[13]}$ Thus, considering the copolymerizability of conjugated dienes with $\mathrm{St}^{\left[{ }^{[13]}\right.}$ we envisioned that a dienyl telluride would copolymerize with $S t$ and induce branching. Herein, we report a new monomer 6, which copolymerizes with $\mathrm{St}$ in the presence of $\mathbf{2}$ in a one-pot synthesis affording structurally controlled HB-PSt (Scheme 1b).

The difference in the C-Te bond dissociation energies (BDEs) of monomer $\mathbf{6}$ and possible intermediates $7, \mathbf{8}$, and $\mathbf{9 a}(\mathrm{X}=\mathrm{TeMe})$ were estimated by DFT calculations, in which model compounds 10,11 , and 12 were used for 7,8 , and $9 a$, respectively. The BDE of 6 is $225 \mathrm{~kJ} \mathrm{~mol}^{-1}$, which is substantially higher than that of 10 $\left(121 \mathrm{~kJ} \mathrm{~mol}^{-1}\right), 11\left(108 \mathrm{~kJ} \mathrm{~mol}^{-1}\right)$, and $12\left(118 \mathrm{~kJ} \mathrm{~mol}^{-1}\right)$. Such an energy difference strongly suggests the selective activation of 10 , 11 , and 12 over $\mathbf{6}$. The similar BDEs of 10 and 11 also indicate the spontaneous formation of a branched structure after 6 has reacted.

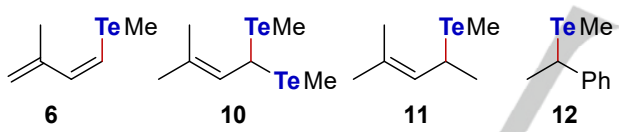

$\operatorname{BDE}(\mathrm{C}-\mathrm{Te})=225 \mathrm{~kJ} \mathrm{~mol}^{-1} \quad 121 \mathrm{~kJ} \mathrm{~mol}^{-1} \quad 108 \mathrm{~kJ} \mathrm{~mol}^{-1} 118 \mathrm{~kJ} \mathrm{~mol}^{-1}$ Bond Dissociation Energy (BDE) (B3LYP/6-31G(d,p)(C,H) + LANL2DZ(Te))

Figure 1. C-Te bond dissociation energies of the branching monomer 6 and model dormant species.

The requisite 6 was prepared by modifying the reported method. ${ }^{[15]}$ The synthesis of HB-PSt 9 a with the dendritic generation $N=3$ was examined by mixing 2,6 , and $S t$ in a molar ratio of $1 / 7 / 500$, as the number of branching points is determined by $[6]_{0} /[2]_{0}=\left(2^{\mathrm{N}}-1\right)$. The resulting mixture was heated at $100{ }^{\circ} \mathrm{C}$ in the presence of 1,4-dimethoxybenzene as an internal standard (Table 1, run 1). ${ }^{[14]}$ The conversion of 6 and St was monitored by ${ }^{1} \mathrm{H}$ NMR and showed nearly linear consumptions of both monomers, though $\mathbf{6}$ was consumed slightly faster than St (Figure 2a). The results clearly confirm the occurrence of statistical copolymerization. The number averaged molecular weight estimated from SEC $\left(M_{\mathrm{n}(\mathrm{SEC})}\right)$ increased with the monomer conversion but deviated significantly from the theoretical values $\left(M_{\mathrm{n} \text { (theo) }}\right)$ with the increase in monomer conversion (Figure $2 \mathrm{~b}$ ). This observation is consistent with the formation of a branched polymer, which has a smaller hydrodynamic volume than its linear analog (see below). SEC traces were unimodal throughout the polymerization and shifted to high molecular weight for monomer conversion (Figure $2 \mathrm{c}$ ), with a dispersity $(\Theta)$ below 2.02 . When the conversions of 6 and St reached $94 \%$ and $71 \%$, respectively, the reaction was quenched by thiophenol, giving terminalhydrogenated $9 b(X=H) \cdot{ }^{[15]}$ The absolute molecular weight determined by multiangle laser light scattering (MALLS) ( $M_{\text {n(MALLS) }}$ $=36.6 \times 10^{3} \mathrm{~g} \mathrm{~mol}^{-1}$, estimated from Mw determined by MALLS and $\Theta$ determined by SEC) was in good agreement with $M_{\text {n(theo) }}$ $\left(37.4 \times 10^{3} \mathrm{~g} \mathrm{~mol}^{-1}\right)$. All the results support the controlled synthesis of HB-PSt.
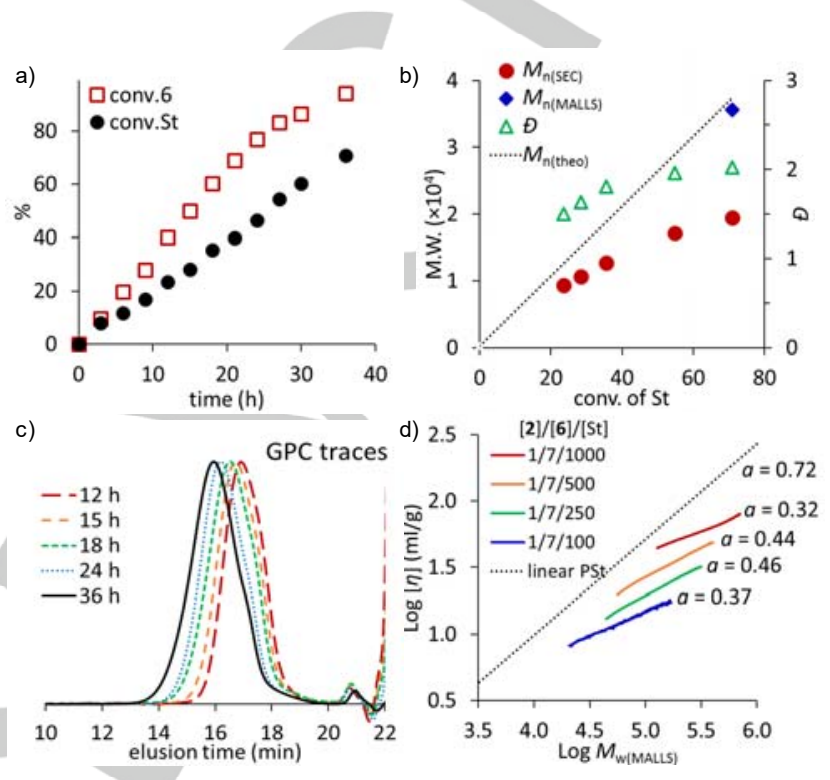

Figure 2. a) Time evolution of the consumption of $\mathbf{6}$ (red empty squares) and St (black dots) by ${ }^{1} \mathrm{H}$ NMR analysis; b) correlation among the St conversion, $M_{\mathrm{n}}$ and $\boxminus$; and c) time evolution of the SEC traces from 12 to $36 \mathrm{~h}$ (Table 1, run 1). d) MHKS plots for linear-PSt $(N=0)$ and 9 bs with $N=3$ at different molecular weights (runs 1-4).

The generality of this method was investigated at first by the control of molecular weight and branching density $\bar{X}_{b r}{ }^{[16]}$ by changing the St/2 ratio to 1000,250 , and 100 while maintaining the $6 / 2$ ratio at 7 (Table 1, runs 2-4). Statistical copolymerization took place, and the conversions of 6 and St reached $>94 \%$ and $>73 \%$ in all cases after $36-48 \mathrm{hrs}$. All the $M_{\mathrm{n}(\mathrm{SEC})} \mathrm{S}$ of the resulting polymers were smaller than the $M_{\mathrm{n} \text { (theo) }} \mathrm{S}$, and the $M_{\mathrm{n} \text { (MALLS) }}$ were in good agreement with the $M_{n \text { (theo) }}$ in all cases (Figure 2d). The SEC traces were unimodal with $Đ$ s of 1.91-2.10. While the dispersity of the PB-PSts was higher than that of linear PSt synthesized by TERP $(\Theta<1.5){ }^{[11 b, 14]}$ the results must be due to the presence of distribution of the branching number and high molecular mass of each branching unit in the HB-PSts.

Mark-Houwink-Kuhn-Sakurada (MHKS) plots of $9 \mathrm{~b}$ prepared in runs 1-4 were estimated from the universal curve calibrated by linear PSt standards and revealed the intrinsic viscosity ([ $\eta])$ of $9 \mathbf{b}$ to be significantly lower than that of linear PSt. In particular, $[\eta]$ decreased with decreasing $\overline{X_{b r}}$. The values of the MHKS constant $a$ of $9 b$ were $0.32-0.46$, which were significantly smaller than that of linear PSt $(a=0.72) .{ }^{[17]}$ All results support the successful synthesis of structurally controlled HB-PSts.

The control of branching number was next examined by changing the $6 / 2$ ratio to 3,15 , and 31 , which correspond to 
dendritic generation $N=2,4$, and 5, respectively, while maintaining the $\mathrm{St} / \mathbf{2}$ ratio as 500 (runs 5-7). Controlled copolymerization was observed for $N=2$ and 4 as judged by unimodal GPC traces, controlled $M_{\mathrm{n} \text { (MALLS) }}$ s, and $M_{\mathrm{n}(\mathrm{SEC})} \mathrm{s}$ smaller than $M_{\text {n(theo) }}$ S. The dispersity increased to 2.74 for $N=4$, but it is still acceptable. In contrast, no controlled copolymerization took place for $N=5$ due to the partial gelation with increasing monomer conversion. This is probably due to the occurrence of intermolecular terminations of the PSt-end radical, which selectively gives coupling products. ${ }^{[18]}$ The MHKS plots of the HBPSts with $N=2-4$ (runs 1, 5, and 6) showed a significant decrease in $[\eta]$ with increasing $\mathrm{N}$ at the same molecular weight. The MHKS constant $a(0.45 \sim 0.47)$ was also significantly smaller than that of linear PSt (see Supporting Info).

Styrenes having functional groups, such as $p$-chloro and $p$ acetoxy styrenes, were also successfully copolymerized with 6 giving the corresponding HB-PSts (runs 8 and 9). In both cases, the monomer consumptions showed similar behaviors with that of styrene, suggesting the occurrence of statistical copolymerization regardless of the substituent (see Supporting Info). The $M_{\mathrm{n}(\mathrm{SEC}) \mathrm{S}}$ were smaller than the $M_{\mathrm{n} \text { (theo) }}$ s, while the $M_{\mathrm{n} \text { (MALLs) }} \mathrm{s}$ were close to $M_{\mathrm{n} \text { (theo) }} \mathrm{S}$ in both cases, indicating the successful formation of highly branched structures. Although the dispersities were relatively high, the SEC traces were unimodal throughout the polymerization in both cases suggesting the formation of controlled branching structures (see Supporting Info).

The method is also applicable to the synthesis of a tadpole block copolymer (run 10). A linear-PSt $\left(M_{\mathrm{n}(\mathrm{SEC})}=18.1 \times 10^{3}, \pm=\right.$ 1.27) synthesized from 2 and St was treated with 6 (7 equiv.) and St (325 equiv.) under the same conditions used above (run 10). After $>99 \%$ and $66 \%$ conversion of 6 and St, the linear-PSt-blockHB-PSt copolymer was obtained (with $M_{\mathrm{n}(\mathrm{SEC})}=25.2 \times 10^{3}, \oplus=$ $\left.1.82, M_{n \text { (MALLS) }}=38.2 \times 10^{3}\right)$. The SEC traces shifted to the higher molecular weight region while remaining unimodal, suggesting the successful synthesis of the desired block copolymer (see Supporting Info).

The branching efficiency of 6 was examined by a deuterium labeling experiment. Key radical intermediate $\mathbf{1 0}$ formed by the cross-propagation of the polystyrene-end radical $(\mathrm{R}=\mathrm{PSt})$ and 6 not only undergoes the desired 1,4-addition giving 11 and finally 9a but also the undesired 1,2-addition giving 12 and then 13 a (Figure 3a). Since the $s p^{2} \mathrm{C}$-Te bond in 13a cannot generate a propagating radical species under the polymerization conditions, no further branching occurs. The $\omega$-end structures of $9 a$ and $13 a$ were analyzed by ${ }^{2} \mathrm{H}$ NMR after the reduction of the polymer-end group by $\mathrm{Bu}_{3} \mathrm{SnD}$, giving $9 \mathrm{c}$ and $13 \mathrm{c}$ (run 11). ${ }^{[19]}$ The ${ }^{2} \mathrm{H}$ NMR of the resulting polymers only showed a single peak at $2.3 \mathrm{ppm}$ corresponding to the benzylic position, and no olefinic signal was detected (Figure $3 b$ ). These results clearly suggest the selective occurrence of the desired 1,4-addition, and the branching efficiency was determined to be $>95 \%$.

The observed regioselectivity is consistent with the theoretical investigation by DFT calculations at the (U)M062X/[6$31 \mathrm{G}(\mathrm{d}, \mathrm{p})(\mathrm{C}, \mathrm{H})+\mathrm{LANL} 2 \mathrm{DZ}(\mathrm{Te})]$ level using a model reaction between $10(\mathrm{R}=\mathrm{H})$ and styrene (see Supporting Info). The activation energy of the 1,4-addition is $21.5 \mathrm{~kJ} \mathrm{~mol}^{-1}$, which is 6.8 $\mathrm{kJ} \mathrm{mol}^{-1}$ lower than that of the 1,2-addition. Furthermore, the formation of the 1,4-addition adduct is highly exothermic with a formation enthalpy of $-78.8 \mathrm{~kJ} \mathrm{~mol}^{-1}$, which is $12.1 \mathrm{~kJ} \mathrm{~mol}^{-1}$ more thermodynamically stable than that forming the 1,2 -adduct.

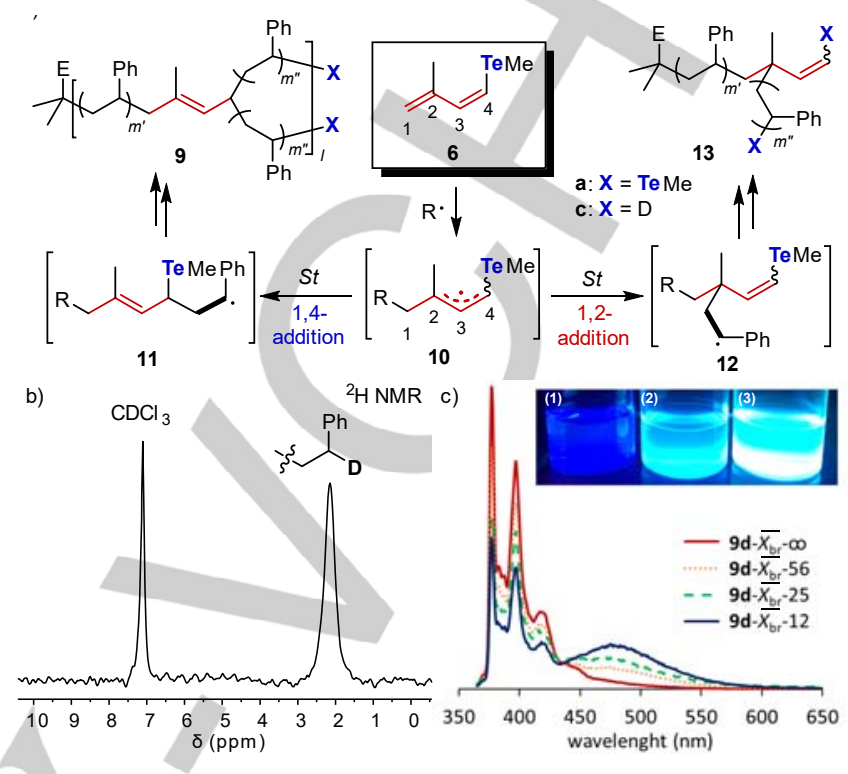

Figure 3. a) Possible reaction pathways via 1,2-addition and 1,4-addition of intermediate radical 10. b) ${ }^{2} \mathrm{H}$ NMR of the $\omega$-end deuterated HB-PSt (run 11). c) Fluorescence spectra of $9 \mathrm{ds}$ with various $\overline{X_{b r}}$ at the same concentration of pyrene $\left(3.0 \times 10^{-4} \mathrm{~mol} \mathrm{~L}^{-1}\right)$ in DMF and optical image of $9 \mathbf{d}-\bar{X}_{b r}-\infty(1), 9 \mathbf{d}-\bar{X}_{b r}-$ 25 (2), and $9 \mathrm{~d}-\bar{X}_{b r}-12$ (3) excited by $365 \mathrm{~nm}$ UV lamp.

The chain-end fidelity and further evidence of the branched structure were obtained by the excimer formation via pyrene introduced at the polymer ends. Thus, 9 a with $N=3$ and different $\overline{X_{b r}}$ prepared using 250,500, and 1000 equiv. of St were photolyzed in the presence of $\mathrm{N}$-(2,2,6,6-tetramethylpiperidine-1oxy-4-yl)-4-(pyren-1-yl)butanamide (pyrene-TEMPO), prepared from 4-(pyren-1-yl)butanoic acid and 4-amino-2,2,6,6tetramethylpiperidine, at room temperature giving 9d (see Supporting Info). ${ }^{[20]}$ The ${ }^{1} \mathrm{H}$ NMR and UV-vis analyses of the product assuming $100 \%$ branching efficiency revealed $86-90 \%$ incorporation of the pyrene, which was almost identical to that of the linear PSt (92\%). The fluorescence spectrum of $9 d$ showed a broad peak at $476 \mathrm{~nm}$ corresponding to the excimer of pyrene, ${ }^{[21]}$ and the intensity of exciplex increased with decreasing $\overline{X_{b r}}$ (Figure 3c). In contrast, no exciplex emission was observed for the linear PSt. These results clearly demonstrate an increase in the local concentration of pyrene by the decrease in $\overline{X_{b r}}$ and support the controlled branching of the synthesized HB-PSts.

In summary, 3D HB-PSts were successfully synthesized from the copolymerization of $\mathbf{6}$ and St with structural control over molecular weight, branching number, branching density, and dispersity. While TERP was used in the current work, the same concept would be applicable to other reversible deactivation (living) radical polymerization methods.

\section{Experimental Section}


Synthesis of Z-1-methyltellanyl-3-methyl-1,3-butadiene (6). ${ }^{[22]}$ Dimethyl ditelluride $(0.64 \mathrm{ml}, 6.0 \mathrm{mmol})$, and $\mathrm{MeOH}(10 \mathrm{ml})$ were charged into a Schlenk tube. $\mathrm{NaBH}_{4}(1.33 \mathrm{~g}, 35 \mathrm{mmol})$ was added in small portions at room temperature until the reddish colour was faded. The mixture was stirred at room temperature for 5 mins and transferred into a Schlenk tube with a J Young valve. 2-Methyl-1-buten-3-yne $(2.8 \mathrm{ml}, 29 \mathrm{mmol})$ was then added at room temperature, and the resulting mixture was heated at $90^{\circ} \mathrm{C}$ for 90 mins after the tube and valve were sealed. The reaction mixture was cooled to room temperature and quenched by addition of deaerated distilled water $(5 \mathrm{ml})$. The resulting mixture was extracted by deaerated hexane $(5 \mathrm{ml})$ for five times. The resulting organic phase was washed by deaerated distilled water $(5 \mathrm{ml})$ for five times. The resulting organic solution was filtered through a plug of $\mathrm{MgSO}_{4}$, and solvent was removed under vacuum to give a reddish oil $(1.83 \mathrm{~g}, 72 \%$ yield containing $3 \%$ of regioisomer). The part of the crude product $(0.30 \mathrm{~g})$ was purified by preparative SEC giving $0.20 \mathrm{~g}$ of 6 as an orange liquid in $66 \%$ yield containing $3 \%$ of regioisomer. ${ }^{1} \mathrm{H} \mathrm{NMR}\left(\mathrm{CDCl}_{3}\right)$ of the major isomer; 1.89 (s, 3H), $1.96\left(\mathrm{~s}\right.$, Te satellite with $\left.J_{\mathrm{HTe}}=22.5 \mathrm{~Hz}, 3 \mathrm{H}\right), 4.80(\mathrm{~s}, 1 \mathrm{H}), 5.06(\mathrm{~s}$, $1 \mathrm{H}), 6.67(\mathrm{~d}, J=10.5 \mathrm{~Hz}, 1 \mathrm{H}), 6.80\left(\mathrm{~d}, J=10.5 \mathrm{~Hz}\right.$, Te satellite with $J_{\mathrm{HTe}}=$ $23.9 \mathrm{~Hz}, 1 \mathrm{H}$ ); Several signals could be characterized to the minor regioisomer; 2.00 (dd, $J=0.68 \mathrm{~Hz}, J=1.43 \mathrm{~Hz}, 3 \mathrm{H}), 2.00(\mathrm{~s}, 3 \mathrm{H}), 5.12(\mathrm{~m}$, $1 \mathrm{H}), 5.17(\mathrm{~m}, 1 \mathrm{H}), 5.52(\mathrm{~d}, J=0.48 \mathrm{~Hz}, 1 \mathrm{H}), 6.08(\mathrm{~d}, J=0.48 \mathrm{~Hz}, 1 \mathrm{H}) ;{ }^{13} \mathrm{C}$ NMR $\left(\mathrm{CDCl}_{3}\right)-15.72,22.09,105.26,115.05,138.84,144.07$; El HRMS Calcd for $[M]+, 211.9845$, found 211.9852; IR (neat) 3076, 2969, 2925, 1622, 1619, 1566, 1453, 1435, 1369, 1330, 1301, 1237, 1224, 1178, 885.

Typical example for the synthesis of HB-PSt 9 (Run 1). A solution of $\mathbf{2}(1.8$ $\mu \mathrm{l}, 0.010 \mathrm{mmol}), 6(9.5 \mu \mathrm{l}, 0.070 \mathrm{mmol}), \mathrm{St}(0.57 \mathrm{ml}, 5.0 \mathrm{mmol})$ was heated at $100{ }^{\circ} \mathrm{C}$ in the dark for 36 hours. During the polymerization, $10 \mu$ of the reaction mixture was taken as the monitoring sample each time. After the NMR measurement, $\mathrm{PhSH}(5 \mu \mathrm{l}, 0.049 \mathrm{mmol})$ was added to the NMR sample solution at room temperature. After $30 \mathrm{mins}$ at this temperature, the solution was used for SEC measurement. The polymerization was quenched by putting the reaction vessel in a freezer at $-20^{\circ} \mathrm{C}$ for 5 mins. Conversion of $6(94 \%)$ and St $(71 \%)$ was determined from ${ }^{1} \mathrm{H}$ NMR spectroscopy. The crude mixture was dissolved in anhydrous THF (5 ml), and $\mathrm{PhSH}(10 \mu \mathrm{l}, 0.098 \mathrm{mmol})$ were added at room temperature. The resulting solution was stirred for 2 hours at room temperature and precipitate in $\mathrm{MeOH}(100 \mathrm{ml}$ ) twice to obtain $0.22 \mathrm{~g}$ (yield $41 \%$ ) of product, which was analyzed by the SEC-MALLS $\left(M \mathrm{n}(\mathrm{SEC})=20.4 \times 10^{3} \mathrm{~g} \mathrm{~mol}^{-1}, D=\right.$ $\left.1.99, M_{\text {n(MALLS })}=36.6 \times 10^{3} \mathrm{~g} \mathrm{~mol}^{-1}\right)$.

\section{Acknowledgements}

This work was partly supported by the JSPS KAKENHI Grant No. 16H06352. The computational studies were supported by the Super Computer Laboratory, ICR, KU.
Keywords: Hyperbranched polymer - TERP • dienyl telluride • control radical polymerization

[1] N. Hadjichristidis, M. Pitsikalis, S. Pispas, H. latrou, Chem. Rev. 2001 101, 3747-3792; B. I. Voit, A. Lederer, Chem. Rev. 2009, 109, 59245973; D. Yan, C. Gao, H. Frey, John Wiley \& Sons, Inc., Hoboken, New Jersey, 2011

[2] M. Jikei, M. Kakimoto, Prog. Polym. Sci. 2001, 26, 1233-1285; C. Gao D. Yan, Prog. Polym. Sci. 2004, 29, 183-275; D. Astruc, F. Chardac, Chem. Rev. 2001, 101, 2991-3023; U. Boas, M. H. Heegaad, Chem. Soc. Rev. 2004, 33, 43-63.

[3] D. A. Tomalia, J. Christensen, U. Boas, Dendrimers, Dendrons, and Dendritic Polymers, Cambridge University press, New York, 2012; D. A Tomalia, H. Baker, J. Dewald, M. Hall, G. Kallos, S. Martin, J. Roeck, J. Ryder, P. Smith, Polym. J. 1985, 17, 117-132; S. M. Grayson, J. M. J. Fréchet, Chem. Rev. 2001, 101, 3819-3867.

[4] P. J. Flory, J. Am. Chem. Soc. 1952, 74, 2718-2723; Y. H. Kim, O. W. Webster, J. Am. Chem. Soc. 1990, 112, 4592-4593.

[5] J. M. J. Fréchet, M. Henmi, I. Gitsov, S. Aoshima, M. R. Leduc, R. B. Grubbs, Science 1995, 269, 1080-1083; C. J. Hawker, J. M. J. Fréchet, R. B. Grubbs, J. Dao, J. Am. Chem. Soc. 1995, 117, 10763-10764; B. Liu, A. Kazlauciunas, J. T. Guthrie, S. Perrier, Macromolecules 2005, 38 2131-2136; S. G. Gaynor, S. Edelman, K. Matyjaszewski, Macromolecules 1996, 29, 1079-1081; K. Sakamoto, T. Aimiya, M. Kira, Chem. Lett. 1997, 1245-1246.

[6] K. Min, H. Gao, J. Am. Chem. Soc. 2012, 134, 15680-15683.

[7] R. Hanselmann, D. Hölter, H. Frey, Macromolecules 1998, 31, 37903801.

[8] Y. Ohta, S. Fujii, A. Yokoyama, T. Furuyama, M. Uchiyama, T. Yokozawa Angew. Chem. Int. Ed. 2009, 48, 5942-5945.

[9] Y. Shi, R. W. Graff, X. Cao, X. Wang, H. Gao, Angew. Chem. Int. Ed. 2015, 54, 7631-7635.

[10] Y. Lu, T. Nemoto, M. Tosaka, S. Yamago, Nature Commun 2017, 8 1863.

[11] S. Yamago, K. lida, J. Yoshida, J. Am. Chem. Soc. 2002, 124, 1366613667.

[12] S. Yamago, Chem. Rev. 2009, 109, 5051-5068

[13] P. Nesvadba, in Encyclopedia of Radicals in Chemistry, Biology and Materials (Eds.: C. Chatgilialoglu, A. Studer), John Wiley \& Sons, Ltd. 2012.

[14] G. Odian, Principles of Polymerization, John Wiley \& Sons, Inc. Hoboken, New Jersey, 2007.

[15] S. M. Barros, M. J. Dabdoub, V. M. B. Dabdoub, J. V. Comasseto, Organometallics 1989, 8, 1661-1665.

[16] S. Yamago, K. lida, J. Yoshida, J. Am. Chem. Soc. 2002, 124, 2874 2875.

[17] S. Yamago, A. Matsumoto, J. Org. Chem 2008, 73, 7300-7304.

[18] The branching density $\overline{\mathrm{X}}_{\mathrm{br}}$ corresponding to as the average monomer unit between branching points is defined as the following equation $\overline{\mathrm{X}_{\mathrm{br}}}=\left([\mathrm{St}]_{0} \times\right.$ Conv.St $) /\left([2]_{0} \times\left(2 \times[6]_{0} /[2]_{0}-1\right) \times\right.$ Conv. 6$)$

[19] J. Xie, POLYMER 1994, 35, 2385-2389.

[20] Y. Nakamura, T. Ogihara, S. Hatano, M. Abe, S. Yamago, Chem. Eur. J. 2017, 23, 1299-1305; Y. Nakamura, S. Yamago, Macromolecules 2015 $48,6450-6456$.

[21] S. Yamago, M. Miyoshi, H. Miyazoe, J. Yoshida, Angew. Chem. Int. Ed. 2002, 41, 1407-1409.

[22] S. Yamago, Y. Ukai, A. Matsumoto, Y. Nakamura, J. Am. Chem. Soc 2009, 131, 2100-2101

[23] S. Farhangi, R. Casier, L. Li, J. L. Thoma, J. Duhamel, Macromolecules 2016, 49, 9597-9604. 


\section{WILEY-VCH}

COMMUNCATION

Table 1. Synthesis of structurally controlled HB-PSts by the copolymerization of $2, \mathbf{6}$, and styrene

\begin{tabular}{|c|c|c|c|c|c|c|c|c|c|}
\hline Run & $\begin{array}{c}{[2] /[6] /[S t]} \\
(N)\end{array}$ & Time $(h)$ & $\begin{array}{c}\text { Conv. } 6 \\
(\%)^{[a]}\end{array}$ & $\begin{array}{l}\text { Conv. St } \\
(\%)^{[b]}\end{array}$ & $\begin{array}{l}M_{n(\text { Theo })} \\
\left(\times 10^{3}\right)\end{array}$ & $\begin{array}{c}M_{\mathrm{n}(\mathrm{SEC})} \\
\left(\times 10^{3}\right)^{[\mathrm{c}]}\end{array}$ & $\begin{array}{l}M_{n(\text { MALLS })} \\
\left(\times 10^{3}\right)^{[\mathrm{d}]}\end{array}$ & $\bigoplus^{[c]}$ & $\overline{X_{b r}}$ \\
\hline 1 & $1 / 7 / 500(3)$ & 36 & 94 & 71 & 37.4 & 20.4 & 36.6 & 1.99 & 27 \\
\hline 2 & 1/7/1000 (3) & 45 & 99 & 73 & 76.6 & 41.7 & 81.3 & 2.10 & 52 \\
\hline 3 & 1/7/250 (3) & 36 & 94 & 78 & 20.6 & 15.8 & 27.1 & 1.91 & 15 \\
\hline 5 & $1 / 3 / 500(2)$ & 48 & 99 & 78 & 41.0 & 28.1 & 44.3 & 1.69 & 65 \\
\hline 6 & $1 / 15 / 500(4)$ & 36 & 94 & 72 & 38.7 & 22.9 & 42.5 & 2.74 & 13 \\
\hline 7 & $1 / 31 / 500(5)$ & 24 & 87 & 69 & 33.5 & 24.0 & N.D. ${ }^{[\mathrm{e}]}$ & 14.3 & 6 \\
\hline $8^{[f]}$ & $1 / 7 / 500(3)$ & 16 & 99 & 78 & 54.8 & 27.7 & 55.1 & 2.68 & 25 \\
\hline $10^{[\mathrm{h}]}$ & 1/7/325 (3) & 36 & 99 & 66 & 40.6 & 25.2 & 38.2 & 1.82 & 17 \\
\hline $11^{[i]}$ & 1/7/500 (3) & 40 & 99 & 76 & 40.2 & 26.7 & 48.5 & 2.07 & 25 \\
\hline
\end{tabular}

[a] Copolymerization was carried out in bulk at $100^{\circ} \mathrm{C}$, and the resulting cured mixture was treated with $\mathrm{PhSH}$ at room temperature in THF. [b] Determined by ${ }^{1} \mathrm{H}$ NMR. [c] Determined by SEC. [d] Calculated from $M_{\text {w(MALLS) }} / \theta$, where $M_{\text {w(MALLS) }}$ was determined from MALLS and $\oslash$ was determined from SEC. [e] Not determined. [f] $p$-Chlorostyrene was used instead of St. [g] $p$-Acetoxystyrene was used instead of St. [h] Linear PSt $\left(M_{\mathrm{n}(\mathrm{SEC})}=18.1 \times 10^{3}, \oplus=1.27\right)$ was used instead of 2. [i] Polymer-end was reduced by $\mathrm{Bu}_{3} \mathrm{SnD}$ (16 equiv.) in the presence of $\mathrm{AIBN}\left(0.2\right.$ equiv.) at $60^{\circ} \mathrm{C}$ in toluene. 
WILEY-VCH

Layout 1:

\section{COMMUNICATION}

Dendritic highly branched polystyrenes (HB-PSts) were synthesized by a one-step copolymerization of a dienyl telluride and styrene in the presence of organotellurium chain transfer agent. The controlled branched structure wa ascertained by several control experiments including structure dependent exciplex formation for the pyrene-functionalized HB-PSts.

Layout 2:

COMMUNICATION

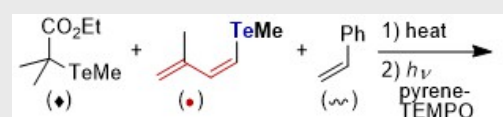

(•)

(•)

Yangtian Lu and Shigeru Yamago*

Page No. - Page No.

One-step Synthesis of Dendritic Highly Branched Polystyrenes by Organotellurium-mediated Copolymerization of Styrene and a Dienyl Telluride Monomer

Page No. - Page No.

Title 